\title{
Factors Influencing Risk Management Decision of Small and Medium Scale Enterprises in Ghana
}

\author{
Anselm Komla Abotsi', Gershon Yawo Dake', Richard Abankwa Agyepong²
}

ABSTRACT

\begin{abstract}
This research seeks to study the factors that enhance or preclude owners of SMEs in Ghana in making risk management decisions. The study was conducted with managers of SMEs in four regions in Ghana. The researchers adopted a quantitative approach and employed STATA 10 and SPSS version 20 in the analysis. Stratified and simple random sampling techniques were used to select the sample units. The probit model was used in the analysis of data. A total of 447 SMEs were sampled for the study, with at least 111 from each of the selected regions. The probit results show that the demographic factors indicate a positive influence on the likelihood that managers will take risk management decisions. All of the business related demographic factors are significant at various levels and positive, except for risk-loving. The economically related factors, such as the estimated amount at risk, the estimated cost of risk management and the estimated total monthly income after tax all have a positive influence on risk management decision making. However, government and tax policies are perceived to negatively influence risk management decisions by managers. We recommend that institutions working closely with SMEs acquire the expertise to train the managers of SMEs on risk management practices.
\end{abstract}

KEY WORDS: $\quad$ knowledge of risk management; small and medium scale enterprises; government and tax policies; risk management decision

JEL Classification: $\quad \mathrm{C} 01 ; \mathrm{C} 05 ; \mathrm{C} 08 ; \mathrm{M} 2 ; \mathrm{M} 21$

${ }^{1}$ University of Education, Winneba - Social Science Department, Ghana; 2 University of Education, Winneba - African Studies Department, Ghana

\section{Introduction}

Risk management can be described as the process of determining the maximum acceptable level of overall risk for engaging in a proposed activity. It involves using risk assessment techniques to determine the

Correspondence concerning this article should be addressed to: Anselm Komla Abotsi, University of Education, Winneba - Social Science Department. P. O. Box 25 Winneba Winneba +233 Ghana. T: +233-244-741-534. E-mail: agrivetent@gmail.com initial level of risk and, if it is excessive, to develop a strategy to ameliorate appropriate individual risks until the overall level is reduced to an acceptable level. Risk management approaches differ from one firm to the next, which, in part, reflects different risk management goals.

According to Saeidi et al. (2013), a paradigm change has occurred in how organizations view risk management, with the current view being more holistic, rather than viewing risk management from a silo-based per- 
spective. Saeidi et al. (2013) suggest the following as the frequently used definition of Enterprise Risk Management (ERM):

"Enterprise risk management is a process, effected by an entity's board of directors, management and other personnel, applied in strategy setting and across the enterprise, designed to identify potential events that may affect the entity, and manage risk to be within its risk appetite, to provide reasonable assurance regarding the achievement of entity objectives" (The Committee of Sponsoring Organizations of the Treadway Commission [COSO], 2004).

Small and Medium Scale Enterprises (SMEs) in Ghana have undergone a series of transformations since the early 1970s in terms of development and promotion. Two of the institutions established to champion these transformations were the Office of Business Promotion (OBP) and the present Ghana Enterprise Development Commission (GEDC). Apart from the support from the Economic Recovery Programme (ERP) instituted in 1983, the National Board for Small Scale Industries (NBSSI) was also established within the then Ministry of Industry, Science and Technology to meet the needs of small and medium scale businesses.

Basing its assessment on the number of employees, the Ghana Statistical Service (GSS) defines small scale enterprises as firms with fewer than 10 employees, and medium and large-sized enterprises as those with over 10 employees. Generally, SMEs in Ghana include:

- Micro enterprises: Employ up to 5 employees with fixed assets (excluding realty) not exceeding the value of $\$ 10,000$

- Small enterprises: Employ between 6 and 29 employees with fixed assets up to $\$ 100,000$

- Medium enterprises: Employ between 30 and 99 employees with fixed assets of up to $\$ 1$ million.

Small and medium scale enterprises have been recognized as the engines to achieve the growth objectives of developing countries because they mobilize idle funds, are labor intensive, employ more labor per unit of capital than large enterprises, promote indigenous technological know-how, are able to compete (but behind protective barriers), use mainly local resources thus have less foreign exchange requirements - cater to the needs of the poor and adapt easily to customer requirements (flexible specialization).
According to Gélinas \& Bigras (2004), a typical SME is dominated by one person, with the owner/manager making all major decisions. These owner/managers are often characterized by limited formal education, limited access to and use of new technologies, limited market information, limited access to credit from the banking sector, and weak management skills. In addition, SMEs experience extreme working capital volatility and the managers lack modern technical knowhow and their inability to acquire modern skills and technologies impede SMEs growth opportunities.

Despite their dynamic role in the country's development, operators of small and medium enterprises face external and internal risks in their businesses, which, threaten the performance, profitability and sustainability of the business. The following external risks are among those faced: natural disasters (e.g., flooding and earthquakes), wars, political crises, and government policies. The following are internal risks pertaining to the running of the business: risk of reduced demand for products and services, risks to ability to compete in the marketplace, high labor turnover, injury, and risks to financial profitability and growth. It is noteworthy that some of the risks that SMEs face can be controlled through the use of appropriate actions, whereas others are unpredictable and uncontrollable. The occurrence of any of these risks may have a disastrous effect on the entrepreneurs' effort for business success, which may lead to bankruptcy and thus deny the country the expected contribution to national growth.

The ability of managers of SMEs to address the dynamics of the emerging global market is also largely influenced by their ability to carefully identify and analyze the type of risks their business faces and then to examine the factors that need to be taken into account to manage them. Management of an enterprise, including managing the risks the enterprise is exposed to and providing other support services, is perceived to be cost prohibitive and non-value adding (Mambula, 2002). Additionally, institutional and legal structures that facilitate the management of risk by SMEs are lacking (Mensah, 2004).

This is the context for the current research, which seeks to study the factors that enhance or preclude owners of SMEs in Ghana in making risk management decisions. This study is especially relevant because it provides policy makers and owners of SMEs with criti- 
cal information pertaining to factors that influence the extent of managers' decisions to undertake risk management practices. The study also contributes to the existing literature on risk management in Ghana, as well as building and testing generic models that can be adapted and applied to ascertain the risk management decision behavior of managers in other developing countries.

The following are factors that enhance or preclude owners of small and medium scale enterprises in Ghana in managing risk to which their enterprises are exposed: demographic, economic, government policies, social, and business characteristics, among others. More specifically, the influence of the following factors will be determined in this research:

- Individual demographic factors, such as age, education, gender, marital status and family size of the manager on Risk Management Decision Making (RMDM)

- Business related demographic factors of the manager, such as experience, knowledge of risk management, risk attitudes, owning businesses elsewhere on RMDM

- Economic

- Government policies and tax on RMDM

- Business characteristics, such as type of business, staff capabilities, number of owners of the business and location of business on RMDM

Risk management should be an integral part of small and medium scale enterprises (Hill, 2000) because SMEs have been recognized as the engines through which the growth objectives of developing countries can be achieved. Therefore, an in-depth knowledge of the factors that influence the decision making of managers of small and medium scale enterprises in Ghana (entrepreneurs) with respect to risk management could contribute to policy decisions that will aid the development and growth of SMEs in Ghana.

\section{Model}

This study modeled the business manager's choice of risk management strategies in an expected utility framework. This model is adopted from Velandia et al. (2009) in their study to find the factors affecting farmers' utilization of agricultural risk management tools. This framework assumes that different business managers assess their end-of-period expected utilities from their own business specific risk and risk preferences. This approach further assumes that the risk management decision fundamentally affects the net return distribution of each business manager.

The business manager then examines his or her net return distribution by considering the certainty equivalent for the risk management decision and calculates its associated reservation cost. The reservation cost is the amount that would make the business manager indifferent to making a risk management decision.

The business manager then compares the reservation cost with the actual cost of adoption of a risk management strategy and makes a decision to adopt a risk management strategy if the reservation cost is larger than the actual cost. This is equivalent to having a larger certainty equivalent net return with the risk management strategy relative to the projected return without the risk management strategy.

More formally, consider a business manager deciding whether to adopt a risk management strategy I ( $\mathrm{i}=1, \ldots, \mathrm{m})$. This business manager evaluates each of these risk management strategies by considering its effect on the returns distribution to a set of assets, A, used in production. These assets have a stochastic rate of return $\tilde{r}_{A}$, with mean $\bar{r}$, and variance $\sigma_{A}^{2}$, reflecting the overall business risks. Financial risk is introduced through the use of debt capital. Utilizing the accounting identity that assets are equal to debt plus equity, $(\mathrm{A}=\mathrm{D}+\mathrm{E})$ and assuming a fixed cost of debt, CD, the expected rate of return to equity $\left(\tilde{r}_{E}\right)$ and the variance of the return to equity $\left(\sigma_{E}^{2}\right)$ can, respectively, be expressed as:

$\tilde{r}_{E}=\left(\frac{A}{E}\right)-C_{D}\left(\frac{D}{E}\right)$

$\sigma_{E}^{2}=(A / E)^{2} \sigma_{A}^{2}$

Given the stochastic environment above, the business manager's certainty equivalent of end-of-period wealth can be approximated as follows (under known sufficient conditions):

$W_{C E}=\bar{W}-\rho \sigma_{W}^{2}$

Where $W_{C E}$ is the business manager's certainty equivalent of end-of-period wealth (W), $\bar{W}$ is the mean of W, and $\sigma_{W}^{2}$ is the variance of $\mathrm{W}$, and $\rho$ is the parameter 
reflective of risk preferences. Maximizing the certainty equivalent rate of return to equity $\left(r_{C E}\right)$ is equivalent to maximizing $W_{C E}$, which can be defined as:

$r_{C E}=\bar{r}-\rho \sigma_{E}^{2}$

From "Equation 1" and "Equation 2", the expression in "Equation 4" can be rewritten as:

$r_{C E}=\tilde{r}_{A}\left(\frac{A}{E}\right)-C_{D}\left(\frac{D}{E}\right)-\rho\left(\frac{A}{E}\right)^{2} \sigma_{A}^{2}$

The effects of using risk management strategies are then assumed to be reflected in the changes in the mean and the variance of the asset return distribution and in the costs $(\mathrm{C})$ of using these strategies for managing risks. Given this cost, the effect of using a particular risk management strategy is to reduce the rate of return to equity by $C / E$. Taking this reduction into account, for every risk management strategy i available to the business manager, the certainty equivalent rate of return to equity can then be redefined as:

$r_{C E, i}=\tilde{r}_{A, i}\left(\frac{A}{E}\right)-C_{D}\left(\frac{D}{E}\right)-\left(\frac{C_{i}}{E}\right)-\rho\left(\frac{A}{E}\right)^{2} \sigma_{A, i}^{2}$

The amount that implicitly equates the expected utilities from using and not using the risk management strategy is the highest cost that a manager is willing to incur for the use of risk management strategies (i.e., the reservation cost $C_{i}^{*}$ ). Hence, per "Equation 5 " and "Equation 6" the reservation cost can be calculated based on:

$\left\{\tilde{r}_{A}\left(\frac{A}{E}\right)-C_{D}\left(\frac{D}{E}\right)-\rho\left(\frac{A}{E}\right)^{2} \sigma_{A}^{2}\right\}=$

$=\left\{\tilde{r}_{A, i}\left(\frac{A}{E}\right)-C_{D}\left(\frac{D}{E}\right)-\left(\frac{C_{i}^{*}}{E}\right)-\rho\left(\frac{A}{E}\right)^{2} \sigma_{A, i}^{2}\right\}$

Solving for $C_{i}^{*}$, we obtain the following expression;

$C_{i}^{*}=A\left(\tilde{r}_{A, i}-\tilde{r}_{A}\right)-\rho^{A}\left(\frac{A}{E}\right)\left(\sigma_{A i}^{2}-\sigma_{A}^{2}\right)$

The expression in "Equation 8" suggests that variables related to asset (A), risk attitudes ( $\mathrm{r}$, and leverage $(\mathrm{A} / \mathrm{E})$, as well as the variables that determine how the risk management strategies affect the mean and variance of the return to assets $\left(\tilde{r}_{A, i}-\tilde{r}_{A}\right)$ and $\left(\sigma_{A, i}^{2}-\sigma_{A}^{2}\right)$, all help determine the manager's reservation cost for $\mathrm{i}$.
Using "Equation 8," it is assumed that the manager will then decide to adopt a risk management strategy if the difference between the reservation cost and the actual cost of using $i$ is greater than zero $\left(\hat{c}^{D}>0\right)$, where $\hat{c}^{D}=\left(C_{i}^{*}-C_{i}^{A c t u a l}\right)$. The difference $\left(\hat{c}^{D}\right)$ is a latent variable, but the adoption decision $\left(Y_{i}\right)$ is observable such that;

$Y_{i}=\left\{\begin{array}{l}1 \text { if } \hat{c}^{D}>0, \\ 0 \text { if } \hat{c}^{D}<0\end{array}\right.$

Where $Y_{i}=1$ if the manager adopt a risk management strategy and $Y_{i}=0$, otherwise.

The formulation in "Equation 9" makes it empirically tractable to estimate the factors influencing the adoption of a risk management strategy. In other words, once a risk management strategy is adopted, it implies that a risk management decision has been made.

\section{Literature Review}

The following section reviews research that has been conducted on the factors influencing the risk management decisions of managers/owners of SME's.

\section{Individual Demographic Factors}

Kouamé (2010) used a multivariate probit approach to show the importance of individual risk aversion, farm size, household size, head of household, and literacy as factors that increase the likelihood of adopting risk management strategies. Velandia et al. (2009) found age to decrease the likelihood of adopting a risk management tool but found farm size to increase the likelihood of adopting a risk management tool. Education was found to both increase and decrease the likelihood of adopting a risk management tool. Valentia et al. (2009) indicated that the negative marginal effect for education in purchasing crop insurance was consistent with the assertion of Shapiro \& Brorsen (1988) that farmers become less risk-averse as they gain more education, thus decreasing the likelihood of using crop insurance as a risk reducing strategy. In contrast, the marginal effect of education on forward contracting and spreading sales is positive and significant. The following hypotheses are formulated based on the literature reviewed:

$\mathrm{HA}_{1}$ : The age of a business owner/manager has a positive effect on the decision to manage risk. 
$\mathrm{HA}_{2}$ : The educational level of business managers has a positive effect on their decision to undertake risk management

$\mathrm{HA}_{3}$ : The marital status of managers has a positive relationship with the managerial decision to undertake risk management.

$\mathrm{HA}_{4}$ : Gender: Males are more likely to undertake risk management decisions than their female counterparts.

$\mathrm{HA}_{5}$ : Family size has a positive effect on the decision to undertake risk management.

\section{Business related demographic factors}

It has been posited that risk perception is an indispensable component of financial decision making and other risk-taking behaviors (Gärling et al., 2010). Byrnes, Miller \& Schafer (1999) (as cited in Gärling et al., 2010) posited in a meta-analysis that men are generally more risk taking than women. The argument is supported by other findings (Donkers \& Van Soest, 1999; Powell \& Ansic, 1997; Weber, Blais, \& Betz, 2002). Miller \& Schafer (1999) also found that parenthood reduces risk taking and older people show a lower risk propensity, which is consistent with the findings by Jianakoplos \& Bernasek (1998). Studies have also shown that measured risk aversion affects occupational and human capital investment decisions. For example, less risk averse individuals are more likely to choose private sector jobs (Pfeifer, 2008) and are more likely to become entrepreneurs (Ahn, 2010). The least risk averse are apparently those who can best assess and manage risks (Cho \& Orazem, 2011).

\section{Hypotheses;}

$\mathrm{HB}_{1}$ : The number of years as a manger in the business has a positive influence on the managerial decision to undertake risk management.

$\mathrm{HB}_{2}$ : Managerial knowledge in risk management has a positive effect on the decision to undertake risk.

$\mathrm{HB}_{3}$ : Risk aversion has a positive effect on the decision to undertake risk management.

$\mathrm{HB}_{4}$ : Managers who own other businesses elsewhere are less likely to manage risk.

\section{Economic Factors}

It is envisaged that the larger the capital base of the enterprise, the more likelihood will its risk be managed because the amount that would be lost could be large. Also depending on the type of risk, the risk might not affect the entire capital base. If the capital at risk is large, it will positively influence the likelihood of adopting a risk management strategy. In addition, depending on where and how the business sourced its capital, the owner may decide either to manage risk or not. If the capital was sourced with collateral, then this is expected to have a positive influence on risk management decision. It is also expected that daily sales/ income influence risk management decision. The larger the income/sales, the larger the positive influence on risk management decision. The proportion of owned acres, off-farm income and level of business risks has been found to significantly affect the adoption of a risk management tool (Valentia et al. 2009).

Hypotheses;

$\mathrm{HC}_{1}$ : The amount of capital at risk has a positive effect on the managerial decision to undertake risk management.

$\mathrm{HC}_{2}$ : The source of business capital has a positive relationship with the managerial decision to undertake risk management.

$\mathrm{HC}_{3}$ : The cost of risk management has a negative effect on the decision to manage risk.

$\mathrm{HC}_{4}$ : The size of monthly business income has a positive effect on the decision to undertake risk management.

\section{Government Policies}

Government policies may either positively or negatively influence risk management decision. For example, on the one hand, a high tax may influence risk management decision positively to minimize losses in order to obtain more revenue to pay the tax. On the other hand, the tax competes with the cost of risk management and other business expenditures and so with a high tax, managers are more likely to compromise the cost of risk management because government tax is statutory. Analytically, Hutter \& Jones (2006) identified two sources of policies that are autonomous and independent from the state; namely the economic sector and civil society as external influences on business risk management. The work of Hutter \& Jones (2006) recognizes that the state has an important role to play(Wolswijk, 2007) but that it also has its limitations, which may be mitigated by other influences beyond the state. 
Hypotheses;

$\mathrm{HD}_{1}$ : Government policies that affect businesses have a positive effect on the managerial decision to undertake risk management.

$\mathrm{HD}_{2}$ : Government tax has a negative effect on the decision to undertake risk management.

\section{Business Characteristics}

Exposure to some risks is also dependent on the location of the enterprise. If the area is risk prone, then it will positively influence the adoption of a risk management strategy. On the issue of the number of staff, the number of workers employed depicts the capital base of the enterprise. Therefore, a higher number of staff has a positive influence on risk management decision. If the type of business is less risky, it is also expected this will have positive effect on the decision to undertake risk management.

\section{Hypotheses;}

$\mathrm{HE}_{1}$ : Business location has a positive effect on the decision to undertake risk management.

$\mathrm{HE}_{2}$ : The business sector has a positive effect on the decision to undertake risk management.

$\mathrm{HE}_{3}$ : The number of staff has a positive effect on the decision to manage risk.

$\mathrm{HE}_{4}$ : The number of persons owning the business has a positive influence on the decision to undertake risk management.

\subsection{Factors that increase the effectiveness of risk management procedures}

Ranong \& Phuenngam (2009) found a set of seven critical success factors that can be used as guidelines on how to increase the effectiveness of risk management procedures: commitment and support from top management, communication, culture, information technology (IT), organizational structure, training and trust. Using the perspective of the financial industry in Thailand, Ranong \& Phuenngam (2009) posit these seven factors can increase the effectiveness of risk management. A holistic approach toward managing an organization's risk is generally known as Enterprise Risk Management (ERM) (Gordon, Loeb \& Tseng, 2009). Saeidi et al. (2013) posit that trust is one of the tools driving impressive risk management and that ERM could be enhanced by improving and maintaining organizational trust.
The literature reviewed suggests that very little work has been performed in establishing the influence of economic factors, government policies/tax and business characteristics in risk management decision making by managers. This situation implies that there is still a knowledge gap about the factors that affect the decision of managers of SMEs to undertake risk management, and this gap is what the current research seeks to close. The study is an empirical examination of the relationship that exists between the factors affecting the managerial decision to undertake risk management.

\section{Methodology}

The study was conducted in four regions in Ghana including Greater Accra Region, Ashanti Region, Western Region and the Northern Region. The population for the study includes all SMEs in these regions.

\section{Data}

\section{Research Design}

This research was designed to take into account the resources available and the time constraint vis-à-vis the need to ensure reliability and validity of the study results. The research adopted a quantitative approach through the use of survey responses from owners/ managers of SMEs in Ghana and used STATA 10 and SPSS version 20 to analyze the responses. The unit of analysis of this study was the individual SMEs surveyed in the selected regions. The owners/managers in the various businesses surveyed were purposely given the opportunity to respond to the questions because they have the best knowledge of the historical data and information about the set up and management of the firms.

\section{Sample Selection and Technique}

To run a regression analysis, a total of 10 cases for each variable are required. To calculate the required sample size, the recommended formula is $50+8^{\star} \mathrm{m}$ where $\mathrm{m}=$ the number of variables in the study. This formula guided the choice of the sample size for the study.

A stratified sampling technique (shown in figure below) was used to put SMEs that are homogeneous in their products and services or operations into subgroups, because the nature of risk varies across firms. 


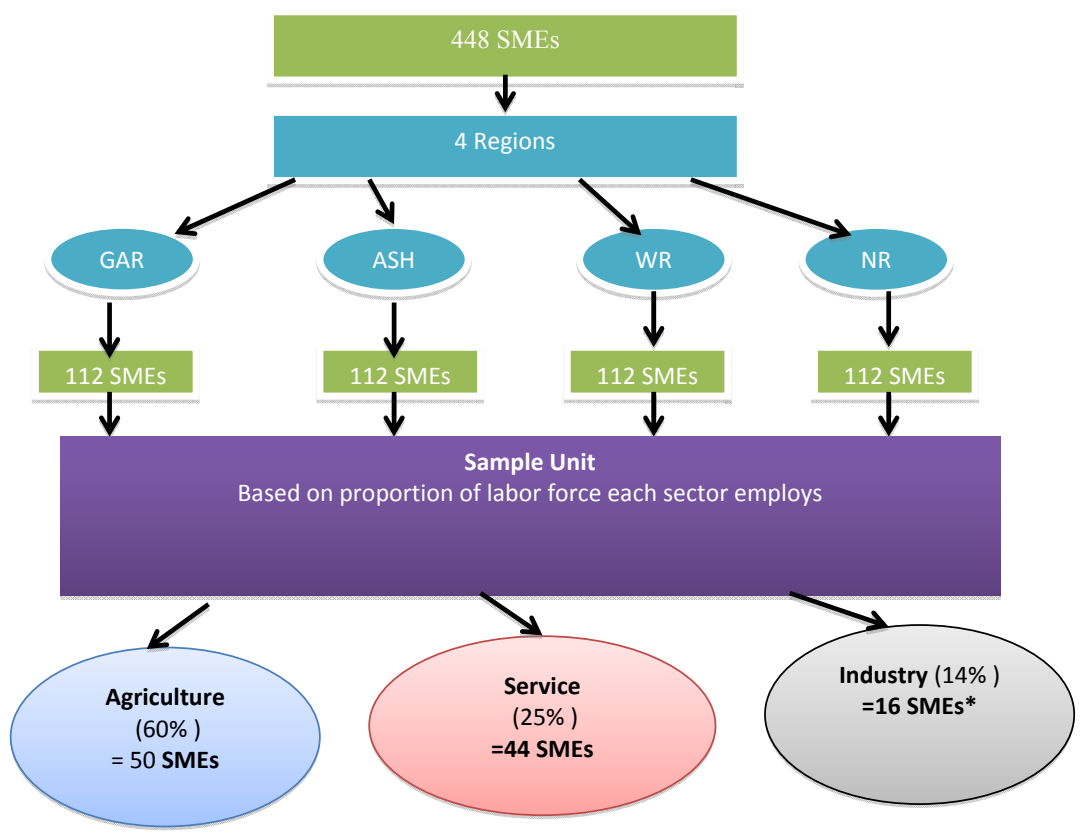

Figure 1. Sampling Distribution

Then, a simple random sampling technique was used to select the sample units. The strata include agriculture, service and the industrial sectors of the economy. The sampling distribution is presented in figure 1 .

A pilot test of the questionnaire was initially conducted on 20 SMEs and the questionnaire was revised based on the information gathered from the field. After administering the questionnaires, the data were passed through a series of scrutiny and cleaning using the statistical software package (SPSS), after which the descriptive phase of the data analysis was complete. Out of 448 questionnaires administered, 447 were retrieved representing a response rate of $99.8 \%$.

\subsection{Data Analysis}

Using "Equation 9," the outcome of interest is risk management decision and this is captured as a binary variable. Both the logit and probit models are often motivated in terms of a latent variable specification, but the choice of models depends on whether the error term is assumed to have a standard logistic distribution or a standard normal distribution. These models assume that there is some continuous latent variable $\mathrm{y}^{*}$ that determines the decision to adopt a risk management strategy. We can think of $y^{\star}$ as the business manager's decision to adopt a risk management strategy. If $\mathrm{y}^{*}$ is positive, the business manager will choose to adopt a risk management strategy and the observed binary outcome equals 1 . Otherwise, the business manager will not adopt a risk management strategy and the observed value equals 0 . Then, the latent variable $\mathrm{y}^{*}$ is modeled by a linear regression function of the independent variables xi and it is assumed that the error term in this equation has a standard normal distribution. Therefore, the probit model is estimated by the method of maximum likelihood estimation.

More specifically, the model is of the form;

$Y_{i}=\beta_{i} X_{i}^{\prime}+\varepsilon_{i}$

Where the dependent variable $\left(Y_{i}\right)$ represents whether a risk management decision has been made, and the independent variables $\left(X_{i}\right)$ include individual demographic, business related demographic economic fac- 
tors, government and business factors, $\beta_{i}$ is a vector of unknown parameters (to be estimated) and $\varepsilon_{i}$ is the stochastic error term.

The regression function includes two types of explanatory variables. The first type can be treated as though they were continuous variables and include: the age of manager(s)/ owners, years of education, household size, number of years as a manager, log of estimated amount at risk, log of estimated cost of risk management, log of estimated total monthly income after tax, total number of employees and number of businesses owned. All the other explanatory variables are binary or dummy variables. These take the value 1 if the individual has a particular characteristic and 0 otherwise. The meaning of the variables used in the analysis is shown in Table 1.

\section{Empirical Results}

\section{Data characteristics}

The data analyzed show that $281(62.9 \%)$ of the respondents are in urban areas, 159 (35.6\%) in the rural areas and 7 in peri-rural. In addition, 115 of the agriculture businesses sampled are located in the rural area while 118 of the service businesses are located in the urban areas. A cross tabulation of business related government policies and their specific effects on businesses, shows that for 7 businesses whose exports and imports are perceived to have been affected by government policies, in 6 cases (representing 86\%) the impact is due to taxation and only in 1 case is the impact due to what businesses had claimed, bad government policy. On the issue of profit, $19 \%$ blamed it on taxation while $93(81 \%)$ attributed it to perceived bad policy. With business security, $5 \%$ blamed it on taxation and $95 \%$ on bad policy. Eleven respondents, representing $100 \%$, attributed the difficulty in loan acquisition to bad policy. It is also worth noting that 52 respondents, representing $11.6 \%$ of the entire sample, indicated a positive impact on their business due to perceived good government policy.

To ascertain the knowledge of managers in taking risk management decisions, respondents were asked whether they take risk management decisions. Approximately $54 \%$ of the respondents positively affirmed to taking risk management decisions. A further probing question asked whether risk management as- sessment has ever been conducted on their businesses. This question revealed that approximately $36 \%$ of the managers had a formal risk assessment conducted for their business, which informed them appropriately on the needed mitigating measures to put into place. The study also elicited from managers the extent of their knowledge of risk management practices on the scale of 1 (lowest knowledge) to 5 (highest knowledge). Approximately $25 \%$ rated their extent of knowledge on risk management practices as high, approximately $5 \%$ rated it lowest and almost $23 \%$ did not rate, which is an indication of no knowledge of risk management. This situation implies that there is still a substantial gap in the knowledge base of managers of SMEs as far as risk management is concerned.

\subsubsection{Descriptive Statistics of the Variables used in} the Regression Analysis

The descriptive statistics of the variables used in the analysis is shown in Table 2 . The results show that $53 \%$ of the managers have made a risk management decision even though $72 \%$ of them have some knowledge of risk management practices. The average age of the managers, the years of education and the years as manager (experience) are 44.5 years, 11.7 years and 12.9 years, respectively. The maximum household size is 18 with the mean being 7 . Almost $50 \%$ of the managers own business elsewhere and approximately $42 \%$ are risk averse. Approximately $57 \%$ of the managers affirm that government policies affect their decision to manage risk and $63 \%$ of the businesses are located in the urban areas.

\section{Probit Regression Results and Discussion}

To differentiate between occupational safety risk measures and business risk measures, the responses on the extent of knowledge of risk management practices, the conduct of risk assessment of the enterprise and the adoption of a risk management strategy (see Table 3) were scored on the scale of 1 to 4 . Any score above 2 implies the manager has been taking risk management decisions. Additionally, once a risk management strategy is adopted, it implies a risk management decision has been made. Table 4 shows the probit regression results. The coefficients on the $\mathrm{X}$ variables tell us how this probability changes with changes in the manager's characteristics. A negative 
Table 1. Variables used and labels

\section{VARIABLE NAME TYPE}

\section{Dependent variable}

Dep_V double

Demographic factors

Q2_Demo_Ag n

YearEdu

mar_mar

Male_Gender

Q7_Demo_Hs e

\section{VARIABLE LABEL}

take risk management decision; Yes/No

age of manager(s)/Biz owners

years of education

Married

Male

household size

\section{Business related demographic factors}

$\begin{array}{ll}\text { Q4_Demo_Yr g } & \text { number of years as a manager } \\ \text { have_RM_KNGE } & \text { have knowledge on risk management } \\ \text { Risk_Loving } & \text { risk loving manager } \\ \text { Risk_Averse } & \text { risk averse manager } \\ \text { have_bus_elswh } & \text { owns business elsewhere }\end{array}$

Economic factors

log_Amt_At k

log_Cost_o t

log_Incom

Bank_Sourc p

CreditU_So p

Gov_Source p

\author{
log of Estimated Amount at Risk \\ log of Estimated cost of risk management \\ log of Estimated Total monthly income after tax \\ source of capital - Bank \\ source of capital - credit union \\ source of capital - government
}

\section{Government policies/tax}

$$
\begin{aligned}
& \text { Govt_Tax_E t } \\
& \text { Gov_Reg_Ef } \sim t
\end{aligned}
$$

government tax affect decision to manage risk

government Policies affect decision to manage risk

\section{Business characteristics}
urban_loc
urban location of business
peri_urban $\sim$ c
peri urban location of business
Agric_Sec
agriculture sector
Industry_Sec
industry sector
Q11_Demo_T s
total number of employees
Q19_Bus_Ow m
number of businesses owned 
coefficient means that managers with those attributes are less likely to take risk management decision, and a positive coefficient means they are more likely to take risk management decision.

All the demographic factors show a positive influence on the likelihood of the managers to take risk management decisions. Apart from the years of education and gender, the other demographic factors are not significant. Years of education is significant at $10 \%$, meaning that managers with more years of education are more likely to take risk management decisions than those with less years of education. Male managers are more likely to take risk management decisions than their female counterparts, and this is significant at $1 \%$. These findings are consistent with earlier findings (Kouamé, 2010; Shapiro \& Brorsen, 1988; Valentia et al. 2009).

All the business related demographic factors are significant at various levels and positive, with the exception of risk loving. The number of years as manager is significant at $1 \%$, indicating that managers with more experience are more likely to take risk management decisions. Knowledge of risk management is also significant at $1 \%$, meaning that managers with some level of knowledge of risk management are more likely to take risk management decision. At the $1 \%$ level of significance, managers who own other businesses elsewhere are inclined to take risk management decisions. These managers are most likely to be risk averse and as part of their risk management plan, decide to establish other businesses elsewhere. Managers who are risk loving are found to be less likely to adopt a risk management strategy. These assertions are consistent with that posited by Cho \& Orazem (2011).

Economic factors, such as the estimated amount at risk, the estimated cost of risk management and the estimated total monthly income after tax all have a positive influence on risk management decision taking. The cost of risk management has a positive influence on managerial decisions with regards to risk management at the $5 \%$ level of significance. In other words, the cost involved in risk management is not a deterrent to risk management decisions and so, in so far as the cost of risk management is less than the capital at risk, managers are motivated to prevent the loss of the capital. The sources of capital have differ- ent influences on risk management decision. Capital sourced from credit unions shows a significantly negative influence on risk management decisions, whereas capital sourced from the government shows a significant positive influence on risk management decision. Capital sourced from the bank is negative but not significant.

Loans from banks and credit unions are either insured and/or have strict collateral requirements and this may influence risk management decisions negatively due to the exhibition of moral hazard on the part of the business managers. The Government of Ghana's (GoG) microfinance programs are targeted at reducing poverty, creating jobs and wealth and are being implemented by the Microfinance and Small Loans Centre (MASLOC, n. d.). In addition to the disbursement of micro and small loans to the identified poor in the various sectors of the Ghanaian economy, MASLOC also provides business advisory services, training and capacity building for small and medium scale enterprises (SMEs). It also collaborates with other institutions to provide the beneficiaries with efficient and effective skills and knowledge required in managing their businesses. No tangible security is required from applicants apart from the group solidarity guarantee. The positive and significant influence of capital sourced from the government on risk management decision can be attributed to this.

The results of government policies and taxes indicate that these factors negatively influence the risk management decision taking of managers. Government tax and government policies affect the decision to manage risk negatively at the $1 \%$ and $10 \%$ level of significance, respectively. An increase in the tax businesses pay on their annual profits (corporate tax) will not lead to a change in output and prices in the short run, all other things being equal. In the long run however, an increase in tax will put firms out of business if they were earning just normal profits before the tax increment, and this will negatively influence risk management decisions. A tax stamp is a statutory tax collected from small-scale selfemployed persons in the informal sector on a quarterly basis in Ghana. Tax stamp rates are determined according to both the type and the size of the business and may influence risk management decisions negatively, because if the tax rate is considered to be 
Table 2. Descriptive statistics of variables used in the analysis

VARIABLE

Dep_V

447

0.5347

0.4994

447

44.5347

12.1385

11.7785

3.7760

20

YearEdu

447

0.7852

0.4111

mar_mar

447

0.5436

0.4987

Male_Gender

447

6.6555

3.2720

18

\section{Business related demographic factors}

Q4_Demo_Yr g
have_RM_KNGE
Risk_Loving
Risk_Averse
have_bus_elswh

447

12.9620

8.5716

43

447

0.72036

0.4493

447

0.2640

0.4413

447

0.4295

0.4956

447

0.4989

0.5006

\section{Economic factors}

$\log$ Amt_At k
log_Cost_o t
log_Incom
Bank_Sourc $\sim p$
CreditU_So $p$
Gov_Source $\sim p$

Government policies/tax

Govt_Tax_E t

Gov_Reg_Ef t

447

447

0.3691

0.5749

0.4831

0.4949

447

0.6286

0.4837

447

0.0157

0.1243

447

Agric_Sec

Industry_Sec

Q11_Demo_T s

Q19_Bus_Ow m

\begin{tabular}{lllll}
447 & 0.4139 & 0.4931 & 0 & 1 \\
447 & 0.2573 & 0.4376 & 0 & 1 \\
447 & 8.3356 & 6.5176 & 2 & 53 \\
447 & 1.3154 & 0.6470 & 1 & 5 \\
\hline
\end{tabular}


Table 3. Knowledge on Risk Management

\begin{tabular}{|c|c|c|c|}
\hline Do you take risk management practices & & Frequency & Percent \\
\hline \multirow[t]{3}{*}{ Valid } & Yes & 239 & 53.5 \\
\hline & No & 208 & 46.5 \\
\hline & Total & 447 & 100.0 \\
\hline \multicolumn{4}{|c|}{ Risk assessment conducted for your business } \\
\hline \multirow[t]{3}{*}{ Valid } & Yes & 162 & 36.2 \\
\hline & No & 285 & 63.8 \\
\hline & Total & 447 & 100.0 \\
\hline \multicolumn{4}{|c|}{ Extent of knowledge in business risk management } \\
\hline \multirow[t]{6}{*}{ Valid } & 1.00 & 23 & 5.1 \\
\hline & 2.00 & 43 & 9.6 \\
\hline & 3.00 & 98 & 21.9 \\
\hline & 4.00 & 112 & 25.1 \\
\hline & 5.00 & 69 & 15.4 \\
\hline & Total & 345 & 77.2 \\
\hline Missing & Applicable & 102 & 22.8 \\
\hline Total & 447 & 100.0 & \\
\hline
\end{tabular}

Note: Data source: Field data

high, managers may sacrifice risk management in favor of their tax obligations. The importance of tax revenue to the Government cannot be overemphasized. This issue notwithstanding, the consideration of short- and long-term elasticities of tax revenues with respect to their bases must not be ignored in tax research (Wolswijk, 2007). This research will help in identifying the most efficient method for increasing tax revenue either by broadening the tax base or by raising the tax rates. To the extent tax base-broadening reduces distortions to economic decisions on saving, investment, consumption and other business related variables, tax base-broadening reforms are identified as growth-oriented reforms.

As specified earlier, some of the managers indicated that taxation and bad policy have affected their profit and business security. A follow-up question to ascertain how taxation and bad policy may have negatively affected their businesses pointed to import policies, high taxes, increase in import duties, increase in exchange rate, increase in bank interest rates and rising cost of business operations among others.

The goal of rationalizing salaries by the government led to the implementation of the Single Spine Salary Structure (SSSS) in 2010, and this had an impact on the economic variables. For example, SSSS led to an increase in the wage bill, which culminated in an increase in money supply. The broad money supply (M2+) grew by 33.2\% in December 2011 and by $24.3 \%$ in December 2012 (Bank of Ghana [BOG], n.d.). The financial institutions, especially the banks, failed to take advantage of the increase in liquidity despite the fact that the bulk of a bank's funds come from deposit mobilization from individuals and businesses in the form of foreign and domestic money market deposit accounts (Centre for Policy 
Table 4. Probit Regression Results

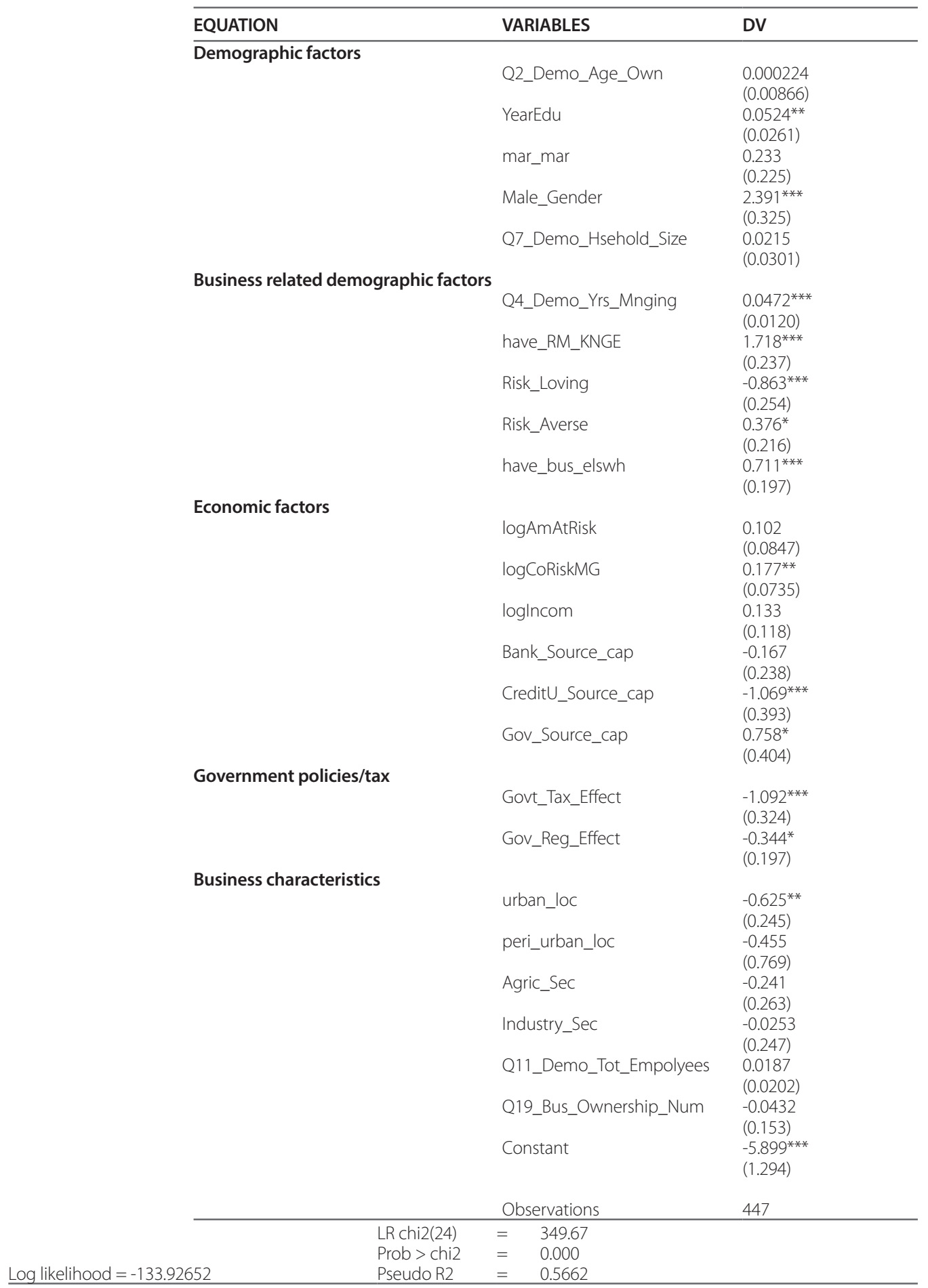

Note: Standard errors in parentheses ${ }^{* * *} p<0.01,{ }^{* *} p<0.05,{ }^{*} p<0.1$ 
Analysis [CEPA], 2011), which led to the increased demand for foreign exchange. The Ghana cedi started depreciating, which made imports relatively expensive with a devastating effect on the expenditures of business enterprises.

The quest to stabilize the Ghana cedi resulted in the benchmark 91-day Treasury bill rate increasing from $10.7 \%$ in December 2011 to $22.4 \%$ in June 2012, and then marginally increasing again in the second half of the year to $23.1 \%$. The 182 -day bill increased from 11.1\% in December 2011 to 22.7\% in December 2012. The 1-year fixed note went up from $11.3 \%$ in December 2011 to $22.9 \%$ in December 2012 (BOG). Interest rates took an upward trend in response to efforts to stabilize the Ghana Cedi. The increase in the cost of funds, strict collateral requirements and inflation expectations, resulted in the tightening of the credit stance for both enterprises and households. This made the business environment unfavorable with a subsequent negative influence on risk management decisions. This situation supports Hutter \& Jones (2006), who found that the state plays an important role, but it also has its limitations that may be mitigated by other influences beyond the state.

Apart from the total number of employees, all the characteristic business factors negatively influence risk management decisions on the part of managers. Oddly, at the $5 \%$ level of significance, businesses in urban areas are less likely to take risk management decision than those in rural areas. Descriptive analysis of the data showed that out of the 281 businesses in urban areas, $64(22.8 \%)$ are agricultural, 99 (35.2\%) industrial and 118 (42.0\%) are services. Also, out of the 159 businesses in the rural areas, $16(10.1 \%)$ are industry, $28(17.6 \%)$ are service and $115(72.2 \%)$ are agriculture. Thus, it can be inferred that the managers of agricultural businesses are better than their counterparts in the industry and service sectors in terms of risk management decisions.

\section{Results of Hypotheses Testing}

The factors hypothesized to affect the risk management decisions of SMEs in Ghana are as follows: individual demographics, business related demographics, economic factors, government policies and business characteristics. The results are shown in Table 5. The results show that, under the demographic factors sug- gested to positively influence risk management decisions, only the hypotheses on the educational level of business managers and gender (males) were accepted at $5 \%$ and $10 \%$ level of significance, respectively. All the hypotheses under the business related demographic factors were accepted at various levels of significance. Under economic factors, the hypothesis on the cost of risk management is rejected at the $5 \%$ level of significance and government source of capital is accepted at the $10 \%$ level of significance. The hypothesis on credit union source of capital is rejected at the $1 \%$ level of significance, meaning that using a credit union as a capital source negatively influences risk management decisions. The hypothesis on government policies is rejected and that on tax is accepted at $10 \%$ and $1 \%$ levels of significance, respectively.

\section{Conclusion and Policy Recommendations}

Small and medium scale enterprises are the engine of growth of the economy and a good provider of employment, and, therefore, they have been one of the major areas of concern for many policy makers. The findings show that apart from years of education and gender, the rest of the demographic variables are not significant, and all the business related demographic factors are significant at various levels and positive, except for risk loving. Government policies and taxes negatively influence risk management decision making by managers. Despite the novel contribution of this paper to the literature on risk management decisions, we were not able to review sufficient literature to validate some of the hypotheses formulated and tested in the analysis. This omission was due to the absence of the literature and is a shortcoming of the paper.

Based on the findings, the following recommendations are made to all stakeholders:

1. The managers of SMEs should recognize that a holistic approach toward managing business risk has generally been recommended to ensure effective risk management. Research has identified the following seven factors that can increase the effectiveness of risk management procedures: commitment and support from top management, communication, culture, information technology (IT), organization structure, training and trust. These factors 
Table 5. Hypothesis results

\section{Null hypothesis on decision to manage risk}

\section{Demographic factors}

HA1: Age of business owner/manager

HA2: The educational level of business managers

HA3: The marital status of managers

HA4: Gender: Males

HA5: Family size

\section{Business related demographic factors}

HB1: The number of years as a manager

HB2: Managerial knowledge in risk management

HB3: Risk aversion

HB4: Managers owning other businesses elsewhere

\section{Economic factors}

$\mathrm{HC1}$ : The amount of capital at risk

HC2: The source of business capital

Bank

Credit union

Government

Reject

Reject at $1 \%$ level of significance

Fail to reject at $10 \%$ level of significance

HC3: The cost of risk management

HC4: The size of business monthly income

\section{Government policies/tax}

HD1: Government policies

HD2: Government tax

\section{Business characteristics}

HE1: Business location (urban)

HE2: The type of business

HE3: The number of staff

HE4: The number of person owning the business

\section{Decision}

Reject

Fail to reject at 5\% level significance

Reject

Fail to reject at $1 \%$ level of significance

Reject

Fail to reject at $1 \%$ level of significance

Fail to reject at $1 \%$ level of significance

Fail to reject at $10 \%$ level of significance

Fail to reject at $1 \%$ level of significance

Reject

Reject at 5\% level of significance

Reject

Reject at 10\% level of significance

Fail to reject at $1 \%$ level of significance

Reject at 5\% level of significance

Reject

Reject

Reject 
can serve as a guide to all managers in taking risk management decisions.

2. The Government of Ghana's (GoG) microfinance programs are targeted at reducing poverty, creating jobs and wealth and are being implemented by the Microfinance and Small Loans Centre (MASLOC). These programs must be enhanced through capacity building, provision of logistics and making enough funds available to serve as many SMEs as possible.

3. Banks, credit unions and other financial intermediaries should add business advisory services, training and capacity building for SMEs emphasizing risk management practices to their loan packages.

4. The Ministry of Trade and Industries (MoTI), the National Board for Small Scale Industries (NBSSI), the Association of Small Scale Industries (ASSI), the Chamber of Commerce $(\mathrm{CoC})$, the Association of Ghana Industries (AGI), banks and other support institutions working closely with SMEs should acquire expertise on risk management practices to train managers of SMEs through periodic workshops and conferences. It must be stated that women are more vulnerable in terms of risk management and so need more attention.

5. Insurance companies should make provisions for SMEs in all sectors (agriculture, industry and service) in terms of policies and make these packages very attractive in order to persuade the managers of SMEs to patronize these packages. Insurance companies should increase the awareness of the existence of such policies.

6. To avoid distorting tax revenue inflows, to ensure high tax elasticities and to prevent distortions to economic decisions on saving, investment, consumption and other business related variables, the Revenue Authority is encouraged to adopt a broad base, low rate approach to taxation. This approach will help managers of SMEs to manage business risk and will contribute to the growth of SMEs in Ghana.

7. Government prudential policies that have an effect on SMEs should be carefully formulated and these policies should be well articulated and explained to stakeholders so that they are not regarded as deterrents to business development in Ghana.

8. The Bank of Ghana through the Monetary Policy Committee should collaborate with the financial institutions to reduce interest rates in order to ameliorate the negative effect of high interest rates on business investment and growth.

9. Information on interest rates by the various financial institutions should be made available by the National Board for Small Scale Industries to prospective business men and women so that they can make informed decisions on when and where to borrow.

\section{References}

Ahn, T. (2009). Attitudes toward risk and self-employment of young workers. Labour Economics, 17, 434-442.

Bank of Ghana (BoG). (n.d.). Accessed 10th June, 2013, Available : http://www.bog.gov.gh/.

Bigras, R. G. (2004). The characteristics and features of SMEs : favourable and unfavourable to logistics integration. journal of small business management 2004-wiley online library, 263-278.

Byrnes, J. P., Miller, D. C. \& Schafer, W. D. (1999). Gender differences in risk taking: A meta analysis. Psychological Bulletin, 125, 367-383.

Centre for Policy Analysis (CEPA). (2011). Ghana Economic Review and Outlook 2009-2012.

Cho, I. S. \& Orazem, P. (2011). Risk Aversion or Risk Management?: How Measures of Risk Aversion Affect Firm Entry and Firm Survival. Working Paper, no. 11016. Iowa State University.

COSO. (2004). Enterprise Risk Management - Integrated Framework (AICPA, Trans.). New York, NY: : Committee of Sponsoring Organizations of the Treadway Commission.

Donkers, B. \& Van Soest, A. (1999). Subjective measures of household preferences and financial decisions. Journal of Economic Psychology, 20, 613-642.

Garling, T., Kirchler, E., Lewis, A. \& van Raaij, W.F. (2009). Psychology, financial decision making, and financial crises. Psychological Science in the Public Interest , 10(1), 1-47.

Gordon, 1. A., Loeb, m. P. \& Tseng, c. y. (2009). Enterprise risk management and firm performance: A contingency perspective. J. Account. Public Policy, 28, 301-327.

Hill, R. (2000). Human Resource development in small organisations. Journal of european industrial training , 24(2/3/4), 105-117. 
Hutter B. M. \& Jones C. J.. (2006). Business Risk Management Practices: The Influence of State Regulatory Agencies and Non-State Sources. Discussion Paper, No: 41.

Jianakoplos, N. A. \& Bernasek, A. (1998). Are women more risk averse? Economic Inquiry, 36, 620-630.

Jianakoplos, N. A. \& Bernasek, A. (2006). Financial risk taking by age and birth cohort. Southern Economic Journal , 72, 981-1001.

Kouamé, E. B. (2010). Risk, Risk Aversion and Choice of Risk Management Strategies by Cocoa Farmers in Western Cote D'ivoire. Accessed 29th April, 2013 , Available: http://www.csae.ox.ac.uk/ conferences/2010-EDiA/papers/267-Kouame.pdf.

Mambula, C. (2002). Perceptions of SME Growth Constraints in Nigeria. Journal of Small Business Management, 40(1) 58-65.

Mensah, S. (2004). A Review of SME Financing Schemes, presented at the UNIDO Regional Workshop of Financing Small and Medium Scale Enterprises.

Microfinance and Small Loans Centre (MASLOC). (n.d.). Accessed 10th June, 2013 , Available: http:// www.masloc.gov.gh/1/About-Medium-andSmall-Loans.html.

Organization for Economic Cooperation and Development (OECD) . (n.d.). Accessed 8th June, 2013. Accessed 10th June, 2013 , Available : http://www. oecd.org/ctp/tax-policy/46605624.pdf.

Pfeifer, C. (2008). A Note on Risk Aversion and Labour Market Outcomes: Further Evidence from German Survey Data. Discussion paper, no. 3523, IZA.

Powell, M. \& Ansic, D. (1997). Gender differences in risk behavior in financial decision-making: An experimental analysis. Journal of Economic Psychology, 18, 605-628.

Ranong P. N. \& Phuenngam W. (2009). Critical Success Factors for effective risk management procedures in financial industries: A study from the perspectives of the financial institutions in Thailand. Umeå School of Business, Sweden. Accessed 2nd June, 2013. , Available: http://umu.diva-portal.org/smash/get/diva2:233985/FULLTEXT01.

Saeidi, P., Sofian, S., Abdul Rasid, S. Z., Saeidi, S. P. \& Saeidi, S. P. . (2013). The Role of Trust in Enterprise Risk Management. International Journal of
Business and Behavioral Sciences, Vol. 3, No.2.

Shapiro, B.I. \& Brorsen, B. W. (1988). Factors Affecting Farmers' Hedging Decisions. North Central Journal of Agricultural Economics, 10:145-153.

Velandia, M. , Rejesus, R. M. , Knight, T.O. \& Sherrick, B. J. (2009). Factors Affecting Farmers' Utilization of Agricultural Risk Management Tools. Journal of Agricultural and Applied Economics , 41, $1: 107-123$.

Weber, E. U., Blais, A. R. \& Betz, N. E. (2002). A domain-specific risk-attitude scale: Measuring risk perceptions and risk behaviors. Journal of Behavioral Decision Making , 15, 263-290.

Wolswijk, G. (2007). Short- and Long-Run Tax Elasticities: The Case of the Netherlands. Working Paper Series, No. 763 .

\section{Acknowledgements}

Funding has been made possible by: Investment Climate and Business Environment (ICBE) Research Fund (joint project of TrustAfrica and IDRC) 
